\title{
A comparative study of structured PVDF fiber/bead composite via electrospinning technique
}

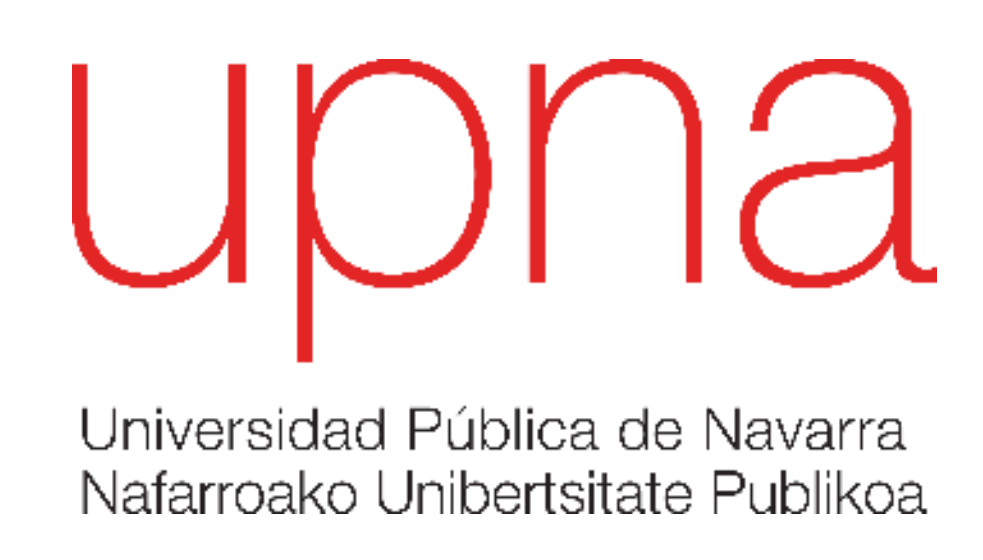

\author{
A. Vicente, P. J. Rivero and R. Rodríguez \\ Engineering Department, Public University of Navarre, Pamplona, Spain \\ Institute for Advanced Materials (InaMat), Public University of Navarre. Campus Arrosadía S/N, 31006, Pamplona, Spain \\ adrian.vicente@unavarra.es
}

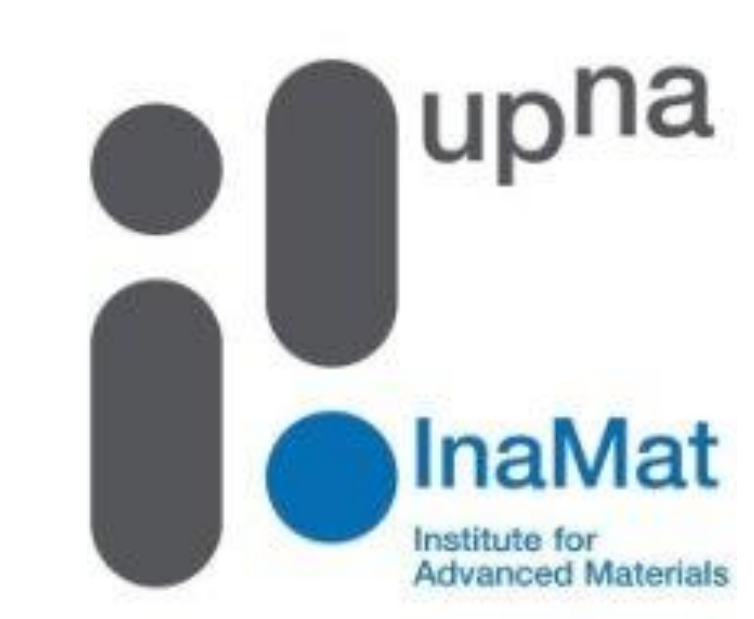

\section{ABSTRACT}

In this work, the electrospinning technique is used for the fabrication of functional PVDF fibers in order to identify and evaluate the influence of the experimental conditions on the nanofiber properties in terms of optical transmittance, wettability and surface morphology. According to this, a matrix of $4 \times 4$ samples has been successfully developed by controlling two operational input parameters such as the resultant applied voltage (from 10 up to $17.5 \mathrm{KV}$ ), and the flow rate (from $800 \mathrm{up}$ to $1400 \mu \mathrm{L} / \mathrm{h}$ ) for a fixed polymeric precursor concentration (15 wt.\%). The experimental results have shown the presence of beads with different shape and size along the electrospun fibers in all the samples of study. The following parameters such as fiber diameter, surface roughness, UV-Vis spectroscopy and water contact angle (WCA) measurements have been deeply analyzed for the optimization of electrospun fiber composite. Finally, on one hand, this study has shown that an increase in the applied voltage has produced a lower light transmittance with the formation of thinner fibers and a lower surface roughness. On the other hand, an increase in the flow rate has produced an increase in the fiber diameter up to a maximum flow rate of $1200 \mu \mathrm{L} / \mathrm{h}$, although the surface roughness has continued increased due to the presence of beads, playing a key role in the wettability properties.

\section{RESULTS AND DISCUSSION}

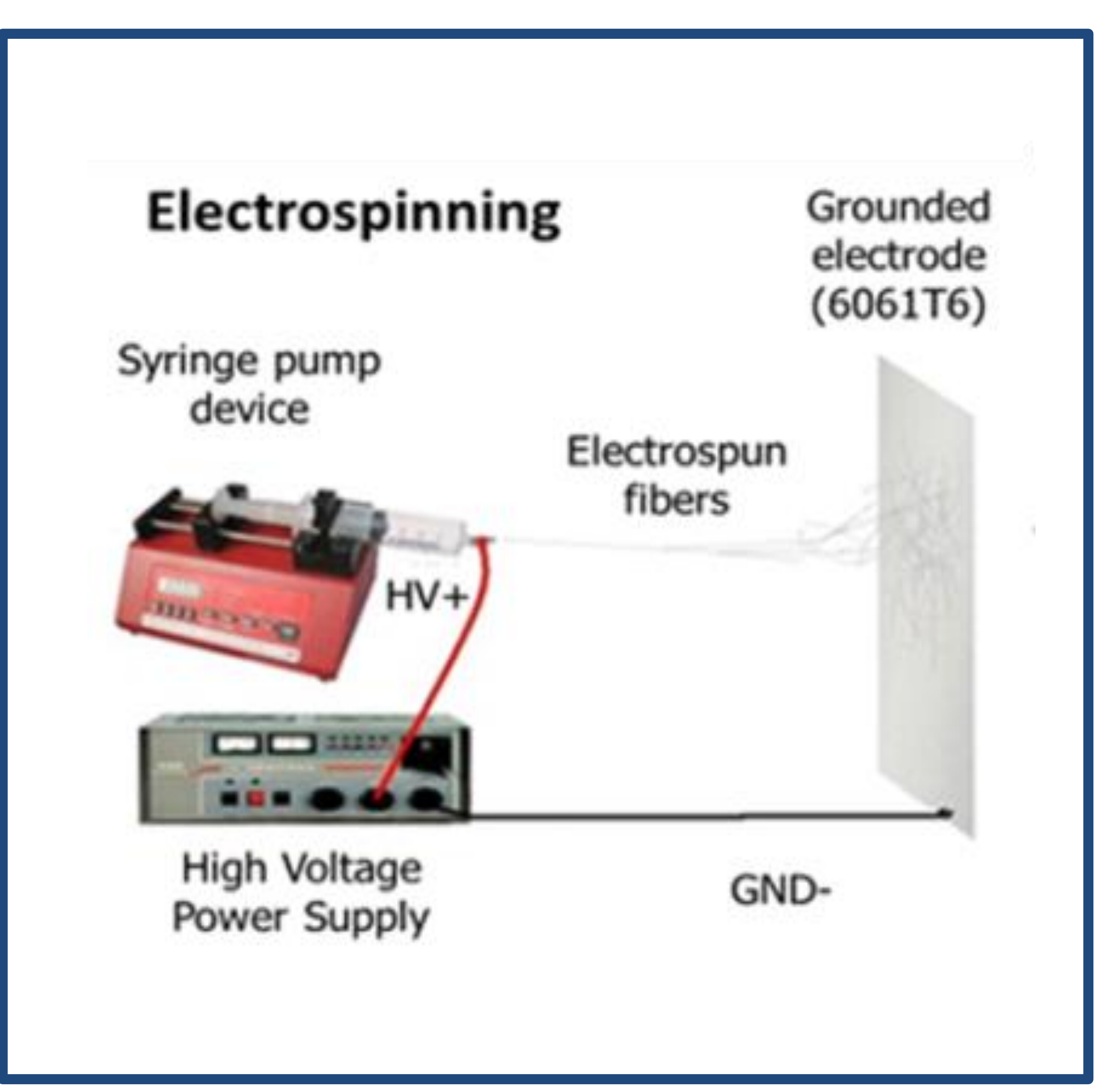

Figure 1: setup experimental for electrospinning process.

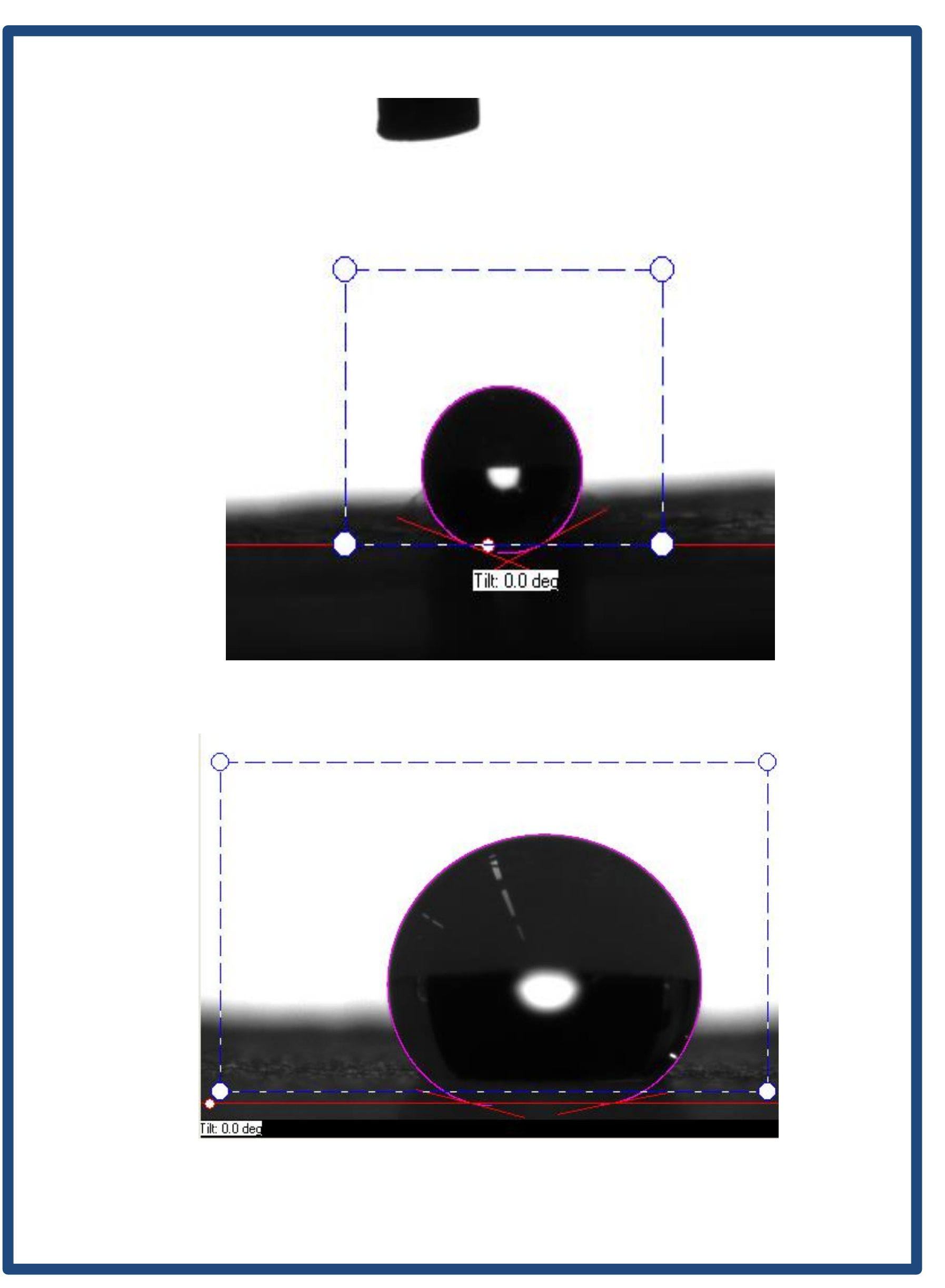

Figure 3: water contact angle (WCA) measurement of the electrospun fibers

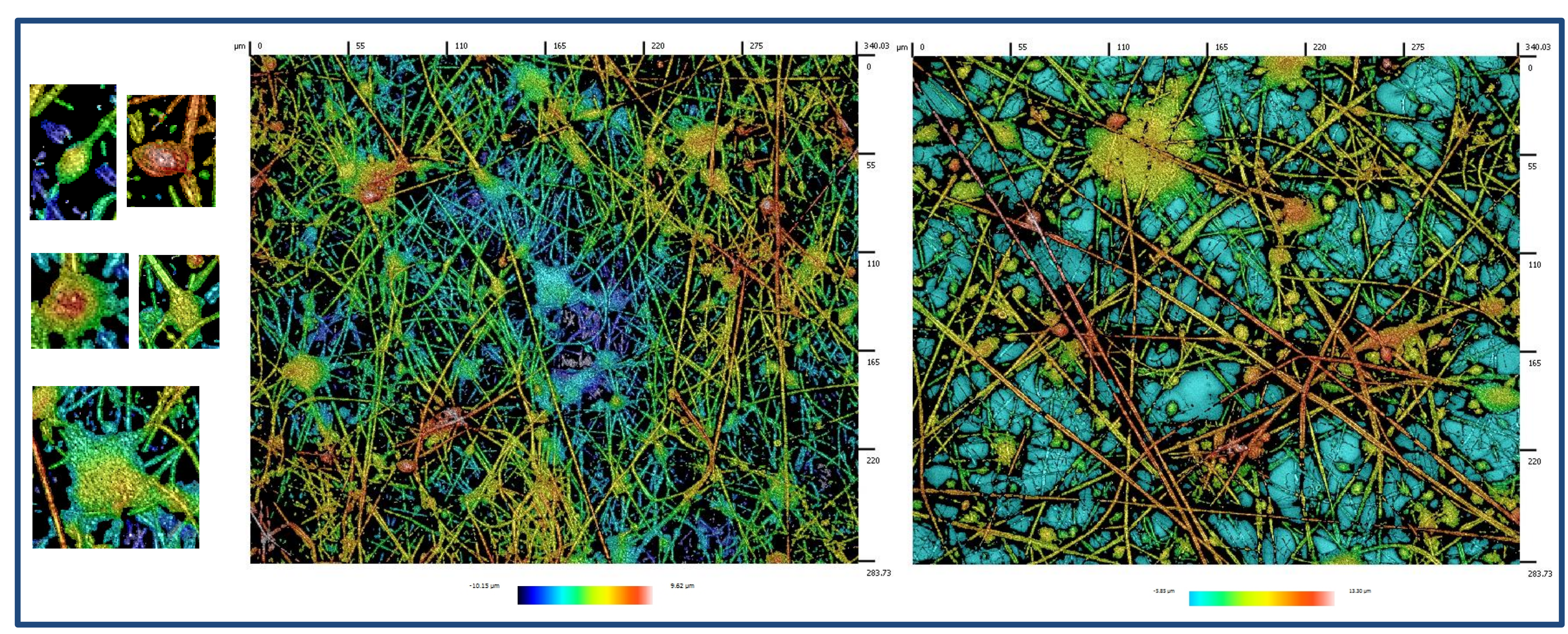

Figure 2: Morphology of the electrospun fibers and beads

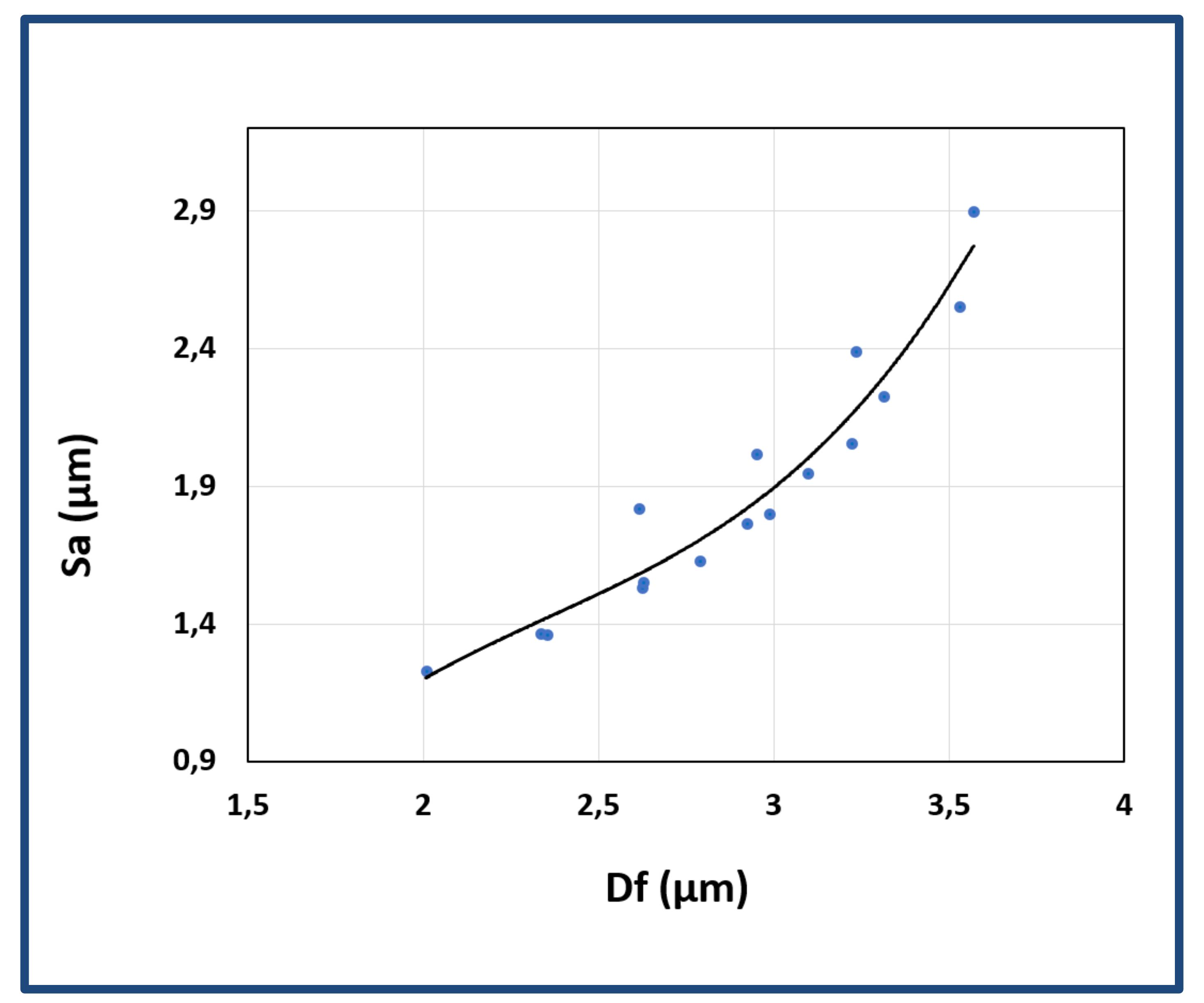

Figure 4: From Linear to exponential relationship between the fiber diameter and the surface roughness due to the influence of beads

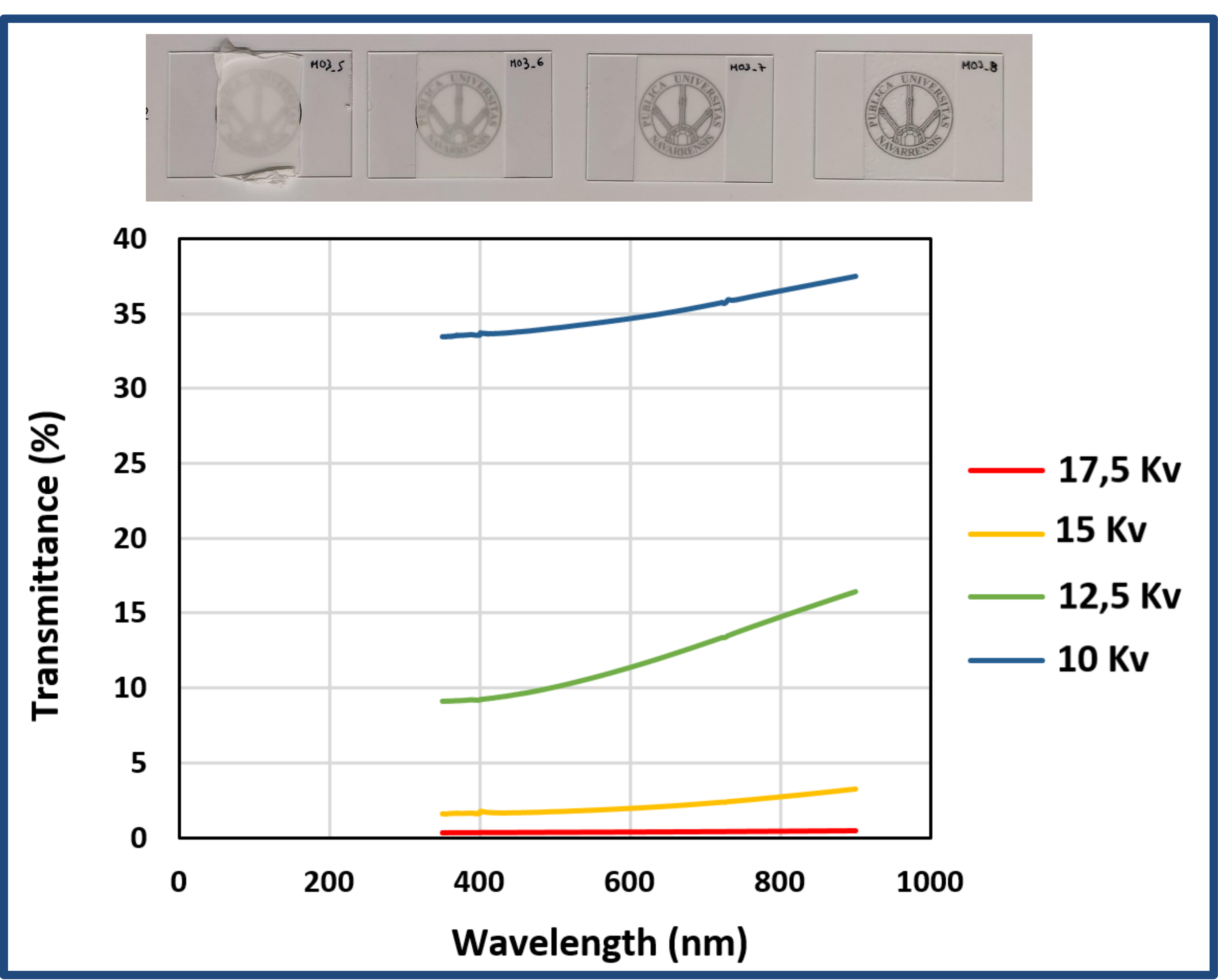

Figure 5: UV-vis spectra of the resultant fibers for a fixed flow rate $(1000 \mu \mathrm{L} / \mathrm{h})$ as a function of the applied voltage

\section{ACKNOWLEDGEMENTS}

This research was funded by the Spanish ministry of science and innovation (Project RTI2018-096262-B-C41-MAITAI, Multidisciplinary Approach for the Implementation of new Technologies to prevent Accretion of Ice on aircraft), and by the Public University of Navarre (Project PJUPNA1929).

\section{REFERENCES}

(1) Rivero, P.J.; Iribarren, A.; Larumbe, S.; Palacio, J.F.; Rodríguez, R. A Comparative Study of Multifunctional Coatings Based on Electrospun Fibers with Incorporated ZnO Nanoparticles. Coatings 2019, 9, 367.

(2) Rivero, P.J.; Redin, D.M.; Rodríguez, R. Electrospinning: A Powerful Tool to Improve the Corrosion Resistance of Metallic Surfaces Using Nanofibrous Coatings. Metals 2020, 10, 350. 